\title{
A Study of Leslie Fielder's Views of American Novels in His Cultural Criticism
}

\author{
FU Channi \\ Hunan University of Science and Technology, China \\ Received: July 28, 2021 \\ Accepted: August 26, 2021 \\ Published: November 30, 2021
}

To cite this article: FU Channi. (2021). A Study of Leslie Fielder's Views of American Novels in His Cultural Criticism. Asia -Pacific Journal of Humanities and Social Sciences, 01 :3, 158-165, DOI:10.53789/j.1653-0465.2021.0103.017.p

To link to this article: https://doi.org/10.53789/ j.1653-0465.2021.0103.017.p

The research project entitled "The Study of Leslie Fielder's Cultural Criticism and Influence” is supported by the Young Foundation of Ministry of Education Research and Fund for Humanities and Social Sciences with No. 18YJC752006.

\begin{abstract}
Leslie Fielder, the distinguished contemporary American cultural critic, focuses his research much on American novels and conducts his research in comparison with European novels. His views of American novels have formed on the basis of the understanding that a novel as a literary genre is a complete and independent system. Thus, his novels cross the barrier between serious classical and popular novels built by traditional American academia. His evaluation of American novels has a historical perspective and a sociological perspective, which integrates psychoanalytic criticism and mythological criticism, and involves the analysis of the characters, themes and essence of American novels, thus forming a unique view of American novels, which has exerted a far-reaching influence on the study of American novels in American academic circles after him, especially on the rise of Gothic novels.
\end{abstract}

Keywords: Leslie Fielder; cultural criticism; American novels; views

Notes on the contributor:FU Channi holds a master's degree of Arts in the English Language. She is an associate professor at Hunan University of Science and Technology. Her academic interest lies in British and American literature and culture.

\section{論萊斯利・費德勒文化批評中的美國小說觀}

\author{
傅嬋妮
}

湖南科技大學

摘 要: 美國當代文化批評先驅萊斯利・費德勒對小說這一文學形式情有獨鐘。他將小說這一文學體裁視為一個 
完整獨立的整體, 這突破了美國傅統學界編織的嚴肃經典小說與大眾流行小說的藩籍。費德勒對美國小說的研 究, 是在與歐洲小說的比較中展開的。他對美國小說的品評擁歷史視野, 持社會學視角, 融精神分析批評、神話批 評於一體, 涉及到對美國小說的人物、主題、本質等問題的評析, 形成了獨特的美國小說觀, 並對他之後的美國學界 内美國小說的研究, 尤其是哥特小說研究的興起產生了深遠的影響。

關鍵字: 萊斯利・費德勒; 文化批評; 美國小說; 小說觀

基金项目: 教育部人文社科青年專案“萊斯利・費德勒文化批評思想及其影響研究 (専案編號: 18YJC752006)”之 階段性成果。

\section{引言}

美國當代文化批評先驅萊斯利 - 費德勒 (Leslie Fiedler, 1917-2003) 被譽為“一流的文化批評家和著名 的猶太批評學者” (1)。費氏對小說這一文學形式情有獨鐘, 其諸多批評著述均圍繞小說展開, 對小說的批評 既構成了他文化批評實踐的重要部分, 也為他贏得了顯赫的學術聲譽。費氏站在與歐洲文學比較的視角, 洞察歐美文學間的關聯與區別, 以宏闊的視野䜿賞美國小說, 認為“美國文學的聲譽主要有賴於小說家”, (2) 美國文學之偉大在於小說之偉大。他發表了諸多關於美國小說的評論,其巔峰之作《美國小說中的愛與死》 更是不遺餘力地探討了美國小說之種種, 被認為“永遠地改變了美國文學對話的術語”。對費氏而言, 小說 就是小說, 不分經典小說或大眾小說。他將小說視作一種完整獨立的文學體裁進行研究, 力圖拓寬經典, 試 圖 “打破學術界建立的將“真” 文學與大眾文學分開的壁壘”, 乐成為跨界遊轉於精英文化與大眾文化間的批 評家, 形成了自己獨特的小說觀。費氏的文化批評受到精神分析、神話批評的影響, 因此他對小說的研究也 常受二者的影響。而費氏自詡為“半個馬克思主義者” ${ }^{5}$ 的身份,讓他的文化批評中的小說觀又保有社會與 歷史維度。美國著名學者文森特・裏奇評論到: “費德勒……採用了一種社會學視角和一種譜系學方法, 抵 制了神話批評把文學文本精神化或寓言化的傾向”。

鑒於費氏的小說觀在其文化批評實踐中的重要性, 梳理與分析他的小說觀是理解其文化批評思想, 把 握他文化批評主要觀點的一枚重要的錀匙。在美國學界,對費氏小說觀的研究主要散落在對他的神話批 評、美國學研究、大眾文學與文化研究、猶太性研究等文化研究之中, 沒有專門針對他小說觀的論述。進人 新世紀, 美國學界對費德勒的研究主要體現在兩方面:一是評述費氏對美國文學與文化批評的貢獻與影響, 尤其自 2003 年費德勒去世到之後的幾年,學界的研究主要圍繞他對新批評的挑戰、對大眾文學與文化批評、 神話批評的貢獻等展開。總體上,美國學界對費氏的貢獻與影響進行了充分的肯定。二是對費氏文化批評 的一些拓展研究,如探討他對義大利文學尤其是中世紀文學與文化的研究、他對天真(innocence) 的理解、他 對猶太作家寫作傳統的研究等。這些研究在一定程度上對了解費氏的小說觀念有所啟發,但大體上新世紀 美國學界對費氏小說觀念的探討不多且零散,沒有形成系統化的討論。國内學界專門有關費氏的學術研究 自新世紀才開始正式起步, 主要聚焦於對他文化批評的總體分析、他的神話批評與其代表作《美國小說中的 愛與死》, 對其小說觀的整體梳理與分析研究尚不多。而研究費氏的美國小說觀有助於增進理解並把握其 文化批評思想及其影響, 也可通過其小說觀瞭解美國作家在歷史進程中的文化建構與表達策略的選擇。劉 於此,本文將主要從三個方面探討費德勒在文化批評實踐中形成的美國小說觀。 


\section{一、美國小說常塑主角一一男孩般的男人}

歐洲的批評家認為所謂的“美國小說” 是“小說”這一文學形式的子類,他們將美國視作一種“反文化” 的存在。費德勒駁斥這一觀點,認為美國並非反文化, 美國小說最多只是歐洲標準的一種變體。他認為美 國沒有歐洲文學的傳統, 由移民組成的新大陸沒有史詩, 歐洲文藝復興時期復興的古體詩歌, 也在美國登上 文化舞臺前就已失去了與當代生活的關聯。在美國, 文學對大多數讀者而言是散文或小說,雖與歐洲文學 有相似之處, 但又異於歐洲小說。費氏指出“在此意義上, 我們的小說似乎不是原始的,而是天真、單純又令 人不安的,幾乎未成年。眾所周知, 美國小說的偉大作品就在圖書館的兒童區, 它們表達的情感就是青春期 前的多愁善感”。美國小說是男孩的文學,他的理由如下:

其一, 美國小說中成熟的女性常缺場。這導致“在美國小說中他們 (作家) 寧可回避成熟女性,卻描寫象 徵著拒絕或令人感到害怕的一些擁有美德或巫術的怪物”。敟氏認為讀者大多渴望在小說中讀到男女的激 情通逅,這一中心情節使文學具備了提供激情與欲望、作為生活中的代償性宣洩的可能,而女性的缺場則讓 這種可能落空。費氏認為美國小說中的這種“畸形” 在於“美國生活中無真正的性生活,因此在美國的藝術 中不可能有對此的書寫”。 這便構成了他小說觀中美國小說異於歐洲小說的一個顯著特點, 即美國小說中 對女人和激情關係的謹慎處理。

其二, “逃走的白人男性” 是美國小說中常塑造的主人公形象。不論是馬克 - 吐溫的《哈克歷險記》, 還 是斯蒂芬 - 克萊恩的《紅色英勇勳章》、理查德 - 亨利 - 達納的航海遊記《兩年水手生涯》等, 主角都是竭力 避免與女性相遇的男性。男主人公似乎對文明和女人感到恐懼, 為尋求自由自在的生活而奔向了自然, 這 仿似一個心智未熟的孩子, 用逃避解決問題。在《瑞普 - 凡・溫克爾》中, 溫克爾為躲避先悍的妻子, 獨自跑 到山中打獵, 喝了仙酒,一醉方休。醒來已是二十年後, 山村巨變, 可他只在意是否仍會遭受女人的專政。 “自那以後, 我們小說中典型的男主人公便成了一個逃跑的男人, 他們勿忙逃人森林, 或漂泊於海洋或河流, 或參與戰鬥——任何可以避免 “文明, 之處都行”。回《瑞普 - 凡 ・溫克爾》以它非凡的想像力宣告了美國本 土小說的誕生, 但也開闢了美國小說中塑造逃走的男主人公之先河。之後的美國小說, 無論是《白鯨》還是 《紅色英勇勳章》等都書寫了主人公從文明社會轉向自然或哥夢的故事。

其三, 美國小說總處於一種“初始” 狀態。“他永遠都在開始,第一次(沒有真正的傳統, 就不可能有第二 次) 表達在大自然前獨自一人的感受, 或者在城市, 與像在任何森林中一樣, 感受到那令人震驚的孤獨”。新 大陸的文學語言實乏,這迫使作家不得不尋找、學習、創造適合他們作品的語言,這就是費氏所言及的“初 始” 狀態。

美國小說中男孩般的主人公不僅存在於《白鯨》和《哈克歷險記》中, 在斯蒂芬 - 克萊恩、海明威、福克 納、舍伍德 - 安德森等人的作品中也均有體現。費氏認為這說明在某種程度上美國小說家們能力有限, 不 得不用他們自創的語言, 寫一批稚氣未脫的男孩般的男主人公, 他們無法也無力面對文明世界的各種紛擾, 只能不斷躲避和逃離, 在大自然中找到一片天地。他也認為這些貫穿於美國作品中的男孩般的男性角色 “是為創立我們稱之為美國角色的我們自己的形象服務……當然,這也是歐洲人將美國看作世界的小男孩 的部分原因所在,即我們製造的奇怪的青少年文學作品”。1 18 世紀下半葉到 19 世紀,正值美國建國並逐漸 擺脫歐洲傳統, 尤其從文化層面脫離歐洲, 探索美利堅民族文化獨立之路的時期, 如同一個男孩, 在成長中 
開始具有自己的個性, 但不成熟。這種文化心理正是美國作家的內心寫照。他們必須面對一切皆無的事 實,並在困惑中開掘一個未知的世界，在這樣的社會文化語境下,費氏認為美國文學的男主角常是透著男孩 氣的男人。

\section{二、美國小說常論主題——“愛”與“死”}

費德勒認為美國小說所敘寫的核心主題是“愛”與“死”,這是美國小說與歐洲小說的又一區別: “為闡明 我國小說傳統異於歐洲大陸之傳統 (我們的生活有別於歐洲的生活), 我發現關注我國重要作家作品中所涉 及的愛與死的主題很有用”。 ${ }^{13}$ 費氏的這一理解體現出弗洛伊德對他的影響。弗洛伊德將愛與死視作人類最 基本的兩種本能。費氏在分析美國小說時援用了 “弗洛伊德的愛神一厄洛斯 (Eros) 和死神一坦納托斯 (Thanatos)”。四弗洛伊德認為厄洛斯代表生存本能, 包含博愛與建設的能量, 坦納托斯代表死亡本能, 激發人 的破壞、仇恨、暴力等毀滅衝動。“愛欲大概是最令人愉悅的預期, 它把自身的焦慮引人反思意識,這就是弗 洛伊德的主題……首詩、一部小說和一部戲劇包含有人性騷動的所有内容, 包括對死亡的恐懼, 這種恐懼 在文學藝術中會轉化成對經典性的乞求, 乞求存在於群體或社會的記憶之中”。回

美國小說中愛的主題, 常令人生疑, 因美國小說中女主人公常缺場, 男主人公向誰表達愛意, 又從誰那 獲得愛與呵護呢? 費氏大膽認為是從其他男性處獲得缺失的女性之愛。從馬斯洛的需求層次理論來看, 這 似乎是個合理的解釋: “人類在生理與安全需要得到滿足後, 便會出現愛、情感與歸屬感的需求……他會比 以前任何時候都強烈地感受到缺乏朋友, 心上人, 妻子或孩子。他極其渴望與一般人建立情感關係, 以在他 的群體或家庭中佔有一席之地”。回這正是逃跑的男主人公的心理困頓。他們都渴求愛以及由愛帶來的歸 屬感。

費氏認為美國小說中這些逃跑的男主人公表面上顯得無拘無束, 自由自在,但心理上他們覺得自己就 像是喪母的流浪兒。費氏在談到《哈克歷險記》時指出: “哈克最終拒絕的社會, 他的 “文明, 本質上是一個 母親的世界, 也就是說是個篤信基督教的女性的世界, 她們在不斷推進的邊疆後維持著基督教信仰”。逃跑 的男主人公沒有母親的呵護、妻子的關愛, 也缺失了信仰的支撑, 内心的無助迫使他們尋找替代, 替代缺失 的女性關懷。“可以肯定的是, 這種替代便藏在大自然的綠心之中: 純真的男人, 好的伴侶, 異教徒或無差恥 之心一一奎奎格或欽加克或黑奴吉姆”。因但費氏又指出, 小說中這些替代女性的純真男人具有兩面性, 他們 既可給予男主人公以愛與歸屬感, 又可成為他們的哥夢。如《最後的莫西幹人》中的欽加克其實也是陰暗的 墓地殺手, 《哈克歷險記》中的吉姆也會拿剃䰅刀指向主人的喉嚨。但男主人公們似乎不管不顧, 這足以證 明當他們走出文明, 獨自面對大自然時, 是多麼需要關心、眷注等愛的形式以安撫內心, 慰藉靈魂。

費氏認為, 由於愛的缺失, 美國小說中的男主人公與其他男性在朝夕相伴中萌生了眷戀之情。美國小 說中的愛情書寫常被表達為跨種族間的男性情誼: “這一種族間的男性情誼由庫珀首創, 目的是減輕早期從 歐洲移民過來的美國人對待美洲原住民而產生的罪惡感和恐懼感”。因費氏的這一解讀與上世紀 60 年代多 元文化主義興起不無關係。美國少數族裔將多元文化主義作為其文化政治與思想武器, 向主流群體的一元 文化主義的霸權理想挑戰, 開始了種族復興之路。費氏在其文化批評中關注種族與性別, 研究併發掘美國 文學作品中跨種族間的男性情誼, 欲通過文學研究傳達出他文化批評背後的政治動因與多元文化主張。他 坦誠地說到: “我大半輩子關注的都是種族間男性關係的政治意義,但我最近意識到它也有宗教意義”。 
什麼是費氏所指的跨種族男性關係的宗教意義? 他用《聖經》中 “男人 (亞當) -女人 (夏娃) - 蛇-伊甸 園” 的原型進行了分析。男女在伊甸園的平靜生活被蛇的闖人破壞, 蛇說服男女偷吃禁果, 導致男女違抗上 帝命令,被逐出伊甸園。蛇是天堂生活的毀滅者。費氏發現男人、女人和蛇三原型也出現在美國小說中。 如在皮䙮子系列故事裏, “是男人在平和的生活中, 愛著蛇, 也就是欽加克 (Chingachgook)。庫珀幾次告訴我 們, 這個名字翻譯成英文就是 ‘大蛇”。女人是闖人者, 想和男人建立關係, 卻最終把他們都趕出了人間天 堂。庫珀並沒有將這地方描繪成可陶冶思想,增進情感的伊甸園, 而是無人涉足的荒野”。在皮襪子系列 中,主人公邦波儘管有女性垂青,卻拒絕與女性建立關係,他更願意與其男性夥伴呆在荒野。因此,在費氏 眼中“男人-女人-蛇-伊甸園” 的模式轉變為 “男人-蛇-女人-荒野”的模式,蛇替代女人,女人成了破壞者, 伊甸園變為了荒野。根據費氏對美國小說的普遍理解, 原型變為了 “白人男性-非白人男性-女人-大自然” 的模式。在美國小說中非白人男性取代女性,在大自然中與白人男性建立了跨種族的戀情。“它們美國小 說更為熯深也更有挑戰性, 而且幾乎無一例外,都是讚美逃避文明,逃避安居樂業,逃避教堂、學堂、逃避“新 世界, 之基督教人文主義倖存下來的一切事物, 只要它們是在女人的監管之下。如此這般, 它們推波助瀾地 打造了地獄般的家的神話”。圈氏如此這般分析,美國小說似乎沉溺於策劃“厭女” 的種種情節：“女人就是 (男人) 為爭取自由, 必須擺脫的一切桎梏”。而擺脫女性,建立的新模式能否長存? 費氏從庫珀的小說中得 出了結論。他認為庫珀一開始便意識到跨種族間的男性關係不可能持續,便在故事中設計了死亡情節。

“死” 是費氏認為的美國小說中的又一重大主題。這一對死亡悲劇的書寫傳統從 1789 年美國誕生的第 一部小說起便開始了。美國的首部小說《憐憫的力量》(The Power of Sympathy, 1789) 的作者威廉 - 希爾 - 布 朗( William Hill Brown) 匿名發表了該小說。小說主人公哈靈頓(Harrington)在經歷愛情的種種煎謷後, 終於 等到結婚。但婚禮當天, 卻得知他與愛人是兄妹關係, 在震驚與痛苦中, 哈靈頓唯有以死解痛。《憐》延續並 模仿了英國作家塞繆兒 - 理查遜作品的感傷風格, 又保留了理查遜小說中對死亡情節的注重。濃烈悲情渲 染下人物的悲慘命運,在審美的化合作用下所激起的洶涌的心理能量喚起讀者對悲劇人物的無盡同情與憐 憫。此作品後,美國文壇刮起了一陣感傷作品風。

在當時, 資本主義迅速發展導致社會矛盾日益加劇, 中下層階級不滿貴族和資產階級的暴虐, 憂愁滿 腹。感傷主義文學正是這種現實中的悲愁、哀怨情緒在文學上的表徵。作家通過這一文學形式反對與抗議 資產階級。感傷主義小說由而也被稱為反資產階級感傷小說。作家們認為“兄妹亂倫是對資產階級最神聖 的禁忌之挑戰…他們將之作為戰勝社會習俗的 “自然的勝利”。在他們有意將妹妹作為首選的情人時, 他們

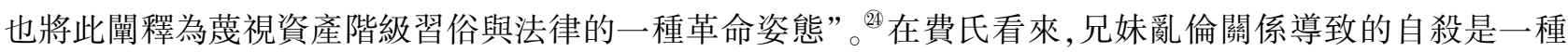
抗議的象徵。“死亡, 同自殺一樣,是一種令基督教正統派震驚的形式,比性更能冒犯資產階級的思想”。5 當 時的作家為反資產階級, 在故事情節的安排上殫精竭慮, 以兄妹亂倫加自殺和死亡的情節,竭力挑戰資產階 級的禁忌, 喚起大眾的憐憫同情, 以文學拒斥和抗議現實的激烈矛盾。繼布朗後, 儘管美國的矛盾隨著社會 的發展不斷改變,但亂倫加死亡的主題卻依然被美國作家不斷敘寫，“與死亡交纏的同胞亂倫在我們的文學 中俯首皆是 (從威廉・希爾・布朗到霍桑, 從坡到威廉・福克納)”。

“死亡” 顯然是美國小說中的悲絕主題,但在小說人物愛情故事的糅合下,死亡被賦予了一絲浪漫色彩, 緩和了死亡製造地恐懼感與殘酷性。同時,小說通過對人物崇高道德和美善心靈的展現,賦予了人物的死 亡以正面價值和意義。死亡仿佛被超越,逝者的美善滌蕩著大地的腥風血雨。人物也在一次次生死抗爭中 走向成熟。對生命的珍惜, 對溫情的珍愛融人了人物的靈魂, 在 “死亡” 情節的強化下, 凸顯出人物更加崇 
高、堅毅、勇敢的形象。而這種人物形象, 在美國作家所描寫的廣哀、雄渾的大自然的映照下, 更顯莊嚴、肅 穆,彰顯出一種超越生死、超然世事的純潔與魅力。

\section{三、美國小說的本質—哥特}

在費德勒之前, 美國學界一直將哥特小說列於大眾文學之屬, 對其鮮有問津。費氏打破高雅文學與大 眾文學之界限, 潛心研究了新大陸的哥特小說, 認為: “我們的美國文學受哥特小說影響最深, 在本質上幾乎 就是哥特小說。一般而言, 歐洲哥特式只是在詩歌或戲劇中達到重要藝術的水準, 而不是在小說中; 在美國 則恰恰相反”。費氏認為美國文學的成就在於小說, 尤其在於哥特小說。“哥特”這一藝術風格, 以恐怖、死 亡、孤獨等表徵人類心理的黑暗與邪惡為䒧術主題。18 世紀後半葉, 哥特小說在英國成為一種小說文類。 19 世紀初,哥特小說登陸美國,並在新大陸紮下根來,影響了一批 19 世紀的美國文壇巨匠。

費氏認為《哈克歷險記》、《紅字》、《白鯨》“三部被普遍認為是我們最偉大作品的小說在主題和氣氛上 都是哥特式的”。《白鯨》的追殺與復仇主題, 人類對自然的野蠻挑戰, 神秘莫測的大自然, 無數鯨骨裝飾的 裴廓德號, 亞哈與白鯨的同歸於盡等黑暗元素, 構成了一個美國式的哥特悲劇故事。《紅字》中丁梅斯代爾 深夜歇斯底里的痛苦吼叫與靈魂的扭曲掙扎, 齊林沃斯瘋狂的内心、詭異的出沒與陰險的復仇計謀, 陰森可 怖的監獄與冷酷無情的絞刑架, 敘寫了一幕有關罪與罰、因與果的悲慘故事。《哈克歷險記》中總讓哈克感 到死氣沉沉的道格拉斯太太家, “國王” 與“公爵” 厚顏無恥的騙人勾當, 以及對他倆行騙懲戒的殘酷私刑, 醉 醺醺、惡狠狠的魔鬼般的哈克父親, 河岸漂流的死屍等細節也讓該小說從一開始就彌漫著一種恐懼的悲傷 基調。除了三部作品的哥特風格外,費氏認為“更重要的是, 在每一本書中, 浮士德的討價還價都是行動的 焦點:海絲特和丁梅斯代爾都象徵性地把自己描繪成黑人的追隨者; 亞哈與費達拉達成了一項不可言喻的 協議, 從地獄的中心攻撃鯨魚; 哈克決定下地獄, 而不是把奴隸歸還給他的合法主人”。②他還發現在美國偉 大作家的其他小說中也有諸多哥特元素。如在麥爾維爾的《皮埃爾》、霍桑的《玉石雕像》、吐溫的《俊瓜威爾 遜》中都表現了濃郁的哥特風格。而在更廣大的美國作品中, 哥特實際以各種形式表現出來, 諸如奴隸制與 黑人的反抗, 印第安戰爭, 城市暴力等。以至於費氏認為 “美國小說在很大程度上是一部恐怖小說”。

“浮士德的討價還價” 即是善與惡的博亦與對決。在歌德的《浮士德》中, 滿腹經綸又迷茫困頓的浮士德 與魔鬼墨菲斯展開靈魂交易, 並在與魔鬼的討價還價中, 挑戰人性又拷問人性。同流合污、貪圖享樂、“執著 塵世”的習氣與“超凡塵世”、向崇高境界飛升的精神是浮士德内在世界不斷角力的兩股勢力。象徵邪惡的 墨菲斯引誘浮士德不斷沉淪, 踐踏事物存在的聖神性與永恆性, 質疑與否定浮士德所建構的傳統的人類價 值與道德觀念。吊詭的是, 墨菲斯的 “惡” 既誘發了浮士德心中的邪念, 又以 “惡”之否定激發了浮士德的潛 力與創造力, 給予其巨大的力量。浮士德成了毀滅者,也成了創造者。

費氏的這一見地指出了 “惡” 在美國小說中展現的積極意義。“討價還價” 的時刻正是惡欲突破善的防 線的關鍵時刻,也是破除陳舊甚至顛覆傳統的關鍵時刻。這一時刻往往是人物對自身潛力的觸底試探, 潛 藏著巨大的毀滅力量,一旦突破,伴之其而來的是毀滅後的重生或是對新事物的創造。在此意義上,美國小 說中的 “惡” 是必要的: “在我們最經久不衰的書中, 哥特式小說, 這一廉價機器總被用來代表人類靈魂和人 類社會隱藏的黑暗……儘管每一個人在他的書中都代表了 “浮士德條約”, 即與魔鬼的交易, 我們的作者一 直認為這是美國經驗的精髓。無論多麼粗劣或諷刺, 恐怖對我們的文學是必不可少的”。在美國小說中, 善 
Asia-Pacific Journal of Humanities and Social Sciences

與惡的討價還價對故事情節的發展、人物形象的塑造起著關鍵的轉化作用。人物在善惡的討價還價中往往 脫胎換骨、洗心革面, 本乏善可陳或誤人迷途的人物最終撥開迷霧, 回歸了通往真善美的坦途。儘管在“惡” 的引誘下,人物會沉淪,禁忌會打破, 善與惡二元對立的交廭與爭鬥難分伯仲,但小說最終邪不勝正的結局, 往往重申與强調了社會的道德與規範, 回歸了對良善美德的謳歌。“總體上,我們的文學有時似乎是一個恐 怖的房間,偽裝成遊樂園中的“歡樂屋”。在那裏我們花錢玩恐怖, 面對最裏面的房間與一系列反光鏡, 這些 反光鏡給我們提供了一千個版本的我們自己的面目”。這是費氏眼中美國小說中 “惡”的另重意義:美國小 說是文學反光鏡中映照的個體影像, 也是美國民族心理的折射, 提供了觀察、審視美國民族心理的機會, 這 對美利堅民族的自省不無積極作用。

為何美國小說對哥特念茲在茲, 以至於美國小說的本質就是哥特呢? 費氏分析到：“美國作家生活在一 個這樣的國家,該國有對歐洲的夢想, 又有實際需要面對的歷史事實; 他們棲身在純真不斷退卻身避的最後 家園——寓居在“前線”, 即生活在原善理論與原罪事實面對面的邊緣”。善與惡的討價還價不僅是小說中 人物行為的焦點,還是現實中不斷發生的真實。十九世紀, 西進運動如火如茶地在美國進行, 領土擴張的野 心,横征暴虐的野蠻行徑, 善惡對決就是真實的美國生活。在充斥著罪惡感的社會苟且, 又要表達這些罪惡 感,樂觀主義㙷得是比清教主義更有效的良藥,尤其隨著西線邊疆不息不絕地向太平洋推進,離東邊清教的 大本營越來越遠。在這種情況下, 美國作家們以為最自在和自然的文學形式便是小說了。小說可以滿足他 們表達純真願景的美好想法, 又可展現西進運動這一獨特的美國經驗與領土擴張中的種種黑暗。

於是美國作家轉向了悲劇小說。社會現實印上了斑斑血跡, 事實本就是一場悲劇。對美國作家來說, 當務之急的“主要技術問題是如何將非悲劇的形式適用於悲劇目的。美國人對暴力的癡迷和在愛情面前的 監尤, 有關暗黑的想像如何在塞繆爾 - 理查森的感傷小說或是沃爾特・司各特爵士的歷史傳奇故事中表現 出來呢?” ${ }^{8}$ 美國作家們尋尋覓䍃, 發現哥特正是這一恰當形式。他們幾番改造與創新, 讓哥特小說成為了處 於當時社會、歷史時期的人們能享用的美國獨異經驗的精神文化食糧: 它可反映美國社會的衝突與爭鬥, 又 不乏浪漫,雖顯得恐怖陰暗,卻又伸張正義,總體上讓讀者體會到了愉悅。“我們國民生活中某種令人無法 釋懷的關切通過這些哥特意象被投射出來: 我們與印第安人、黑人間不清不楚的關係, 我們與自然不清不楚 地相遇, 感覺自己是斌父者的革命人士的內疚之情一一尤其是作者的不安,他們不禁認為創作一部作品就 是撒旦式的反抗。霍桑把《紅字》稱做“地獄之火”, 梅爾維爾認為自己的《白鯨》是一本“邪惡之書””。弗 洛伊德認為文學就是作家的“白日夢”, 在弗洛伊德看來“創造性寫作與實現願望有關,一件藝術品就像白日 夢一樣, 是直接衝動的滿足被抑制, 致使一種結構化的作品被分享的結果……創造力可反映出被擊退的痛 苦影響和被壓抑的性欲與攻擊性有關的衝突的鬥爭”。美國小說家們借助哥特的形式,將無法釋懷的關切、 美國歷史進程中的罪惡與愧疚等種種心理滋味與白日夢般的想像, 借助哥特的形式安全地轉移到文學中, 讓哥特的文學手法演變為心理的、社會的和形而上學的恐怖隱喻,形成了美國小說的哥特底色。

\section{結語}

美國當代文化批評先驅萊斯利 - 費德勒在其文化批評實践中對美國小說的品評持社會歷史視野, 融精 神分析批評、神話批評於一體, 涵蓋了對美國小說的人物、主題、本質等問題的解析,形成了其獨特的美國小 說觀。他主要認為美國小說中的主人公多為稚氣未脫的男人; 美國小說常敘寫愛與死的主題, 跨種族的男 
性愛戀是美國小說中愛的主要形式, 人物的死亡在小說中常富有正面意義; 美國小說本質上是哥特小說, 哥 特形式是表達美國獨異經歷與美國人精神異化的恰當形式,且在作家的不斷敘寫中形成了美國小說的哥特 傳統。他認為美國文學之偉大在於美國小說之偉大, 尤其在於哥特小說之偉大。費氏獨特的美國小說觀拓 寬了文學研究的研究對象, 更新了研究方法, 質疑與解構了正統的的文學思想觀念, 引起了美國學界對美國 小說、尤其對哥特小說的重新審視與評價, 也對之後嚴肅經典文學與大眾流行文學的逐步貫通, 美國學界對 哥特小說研究的熱潮產生了深遠的影響。

\section{注釋}

(1)3 Danie, W. (1999). Leslie Fiedler: Enfant terrible, American Jewish critic, and the other side of Lionel Trilling. In Steven, G. Kellman \& Malin, I. (Eds). Leslie Fiedler and American culture. Newark: University of Delaware Press.

(2)(7) Leslie, F. (1999). A new Fiedler reader. New York: Prometheus Books.

(4) James, M. C. (1999). Celebrating Leslie Fiedler. In Steven, G. Kellman \& Malin, I. (Eds). Leslie Fiedler and American culture. Newark: University of Delaware Press.

(5)223) 萊斯利・費德勒:《文學是什麼? 高雅文化與大眾社會》, 陸揚譯, 譯林出版社,2011 年版, 頁 7 。

(6) 文森特. 裹奇: 《20世紀 30 年代至 80 年代的美國文學批評》, 王順珠譯, 北京大學出版社, 2013 年版, 頁 133。

(9)(10(11)(13)(18)(25)(27)(28)(30)(32(33(34) Leslie, F. (1960). Love and death in the American novel. New York: Criterion Books.

(14) 文森特. 裹奇:《20世紀 30 年代至 80 年代的美國文學批評》, 王順珠譯, 北京大學出版社, 2013 年版, 頁 99。

(15) 哈羅德・布鲁姆:《西方正典一偉大作家和不朽作品》, 江寧康譯, 譯林出版社, 2005 年版, 頁 13 。

(16) Abraham H. M. (1970). Motivation and personality. New York: Harper \& Row Publishers.

(17) Leslie, F. (2008). As free as any cretur.... In Samuele F. \& Pardini, S. (Ed). The devil gets his due. Berkeley: Counterpoint Press.

(19)2021) Leslie, F. (2008). The deerslayer. In Samuele, F. \& Pardini, S. (Ed). The devil gets his due. Berkeley: Counterpoint Press.

(36) Robert, N. E. (2013). Fantasy and beyond: A current developmental perspective on Freud's "creative writers and daydreaming”. In Ethel, S. P., Peter, F. \& Servulo, A. F. (Eds). Freud's “creative writers and day-dreaming”. New Haven: Yale University. 